\title{
A LOGÍSTICA DENTRO DA ORGANIZAÇÃO: CUSTOS, EVOLUÇÃO E PROCESSOS LOGÍSTICOS
}

\section{ARTIGO ORIGINAL}

MAURICIO, João Paulo Meloํ, CHAGAS, Daian Silva das², ROBERTO, José Carlos Alves $^{3}$, SERRA, Meg da Rocha Cunha ${ }^{4}$, FERREIRA, Nelânia Lopes ${ }^{5}$

MAURICIO, João Paulo Melo. Et al. A logística dentro da organização: custos, evolução e processos logísticos. Revista Científica Multidisciplinar Núcleo do Conhecimento. Ano. 06, Ed. 11, Vol. 13, pp. 162-181. Novembro de 2021. ISSN: 2448-0959, Link de acesso:

https://www.nucleodoconhecimento.com.br/administracao/evolucao-e-processos, DOI: 10.32749/nucleodoconhecimento.com.br/administracao/evolucao-e-processos

\section{RESUMO}

O conhecimento sobre a evolução da logística, dos processos de custos e dos processos logísticos que ocorrem na empresa, permite implementar mudanças na forma de gerenciamento das operações e atender aos objetivos estratégicos. Nesse contexto, este estudo teve como objetivo descrever sobre os custos, a evolução e os processos logísticos dentro da organização, apontados na literatura já publicada. Para dar suporte ao estudo foi levantada a seguinte pergunta problema: como ocorre a evolução da logística, os custos e processos? Para isto, foi adotada a metodologia de pesquisa bibliográfica. Ao final, conclui-se que os processos de custos logísticos, bem como a evolução da logística é essencial para empresa, porque possibilita a compreensão dos processos no que concerne a logística dentro da empresa, e

\footnotetext{
${ }^{1}$ Graduando do curso de Ciências Contábeis.

${ }^{2}$ Graduando do curso de Contabilidade.

${ }^{3}$ Orientador. Mestre em Engenharia de produção. Especialista Logística empresarial. Graduado em Administração com Ênfase em Marketing.

${ }^{4}$ Orientadora.

${ }^{5}$ Orientadora.
}

RC: 102110

Disponível em: https://www.nucleodoconhecimento.com.br/administracao/evolucaoe-processos 
ajuda a evitar gastos desnecessários, visto que o objetivo da logística é estabelecer métodos que possibilitem a redução de custos desnecessários às empresas.

Palavras Chaves: Logística, Qualidade, Diminuição dos Custos, Tecnologia.

\section{INTRODUÇÃO}

O conhecimento sobre a evolução da logística, dos processos de custos e dos processos logísticos que ocorrem na empresa, permite implementar mudanças na forma de gerenciamento das operações e atender os objetivos estratégicos.

Considerando que, conforme llos (2016), os custos logísticos correspondem a 11,7\% do PIB brasileiro e os gastos com logística representam $7,6 \%$ da receita líquida, tendo em vista os custos com transporte, estoque e armazenagem, faz-se necessário a mensuração destes e das suas consequências nos custos totais da empresa e dos produtos. Além disso, os custos logísticos podem ser definidos como todos os custos que ocorrem desde o fornecimento de matéria prima até a entrega do produto final ao consumidor.

Ainda que a logística esteja em constante evolução e mudança, uma das suas principais funções é observar todo o processo, desde a produção até a entrega do produto ao consumidor, dando oportunidade aos gestores das empresas de identificar e reduzir custos que influenciam diretamente nos resultados estabilizados, sem interferir na qualidade dos produtos e serviços oferecidos ao consumidor final.

Destaca-se ainda que o custo da implementação de táticas logísticas pode ser visto, a curto prazo, como um alto custo para a empresa, no entanto, os benefícios a médio e longo prazo são diversos. Diante disso, questiona-se: como ocorre a evolução da logística bem como os custos e processos?

Aponta-se ainda que os processos de estocagem, armazenamento e transportes são pontos chaves para o controle de custos dentro de uma empresa. Assim como o uso de novas tecnologias para o gerenciamento de dados e implantação de sistemas, 
onde o controle é feito por meio de dispositivos mecânicos e/ou eletrônicos. Tais inovações colaboram para o progresso e gestão empresarial.

Esse estudo propõe descrever sobre os custos, a evolução e os processos logísticos. Além de conceituar o que é logística, descrever o que é estoque e armazenagem. Portanto, o presente estudo constata que apesar dos benefícios, tais como a redução de gastos sem perda de qualidade dos produtos e serviços prestados ao consumidor final, ainda existem erros graves que precisam ser avaliados para que os impactos sobre a empresa sejam reduzidos.

O estudo foi realizado tendo como metodologia a pesquisa bibliográfica, por meio de artigos e livros, sob a abordagem qualitativa.

\section{FUNDAMENTAÇÃO TEÓRICA}

A fundamentação teórica é sinônimo de referencial teórico, pois trata-se do desenvolvimento dos assuntos mais importantes tratados na pesquisa. Onde consta as citações e os comentários sobre os materiais lidos e publicados. Essa é a parte em que o pesquisador se debruça sobre os subtemas propostos em seu sumário. Consiste ainda em realizar pesquisas com relação ao tema proposto para maior entendimento e conhecimento, assim resultando em uma análise elaborada, através de revisão de trabalhos já publicados. Essa etapa da pesquisa colabora para a coleta de dados, apresentando os seus conceitos (VERGARA, 2016).

\subsection{PROCESSOS LOGÍSTICOS}

Ao falar de logística é comum as pessoas pensarem que se trata de um processo ou um simples método de transporte realizado para entregar um determinado produto, no tempo certo e no local adequado. Hoje em dia, a logística vai além do transporte de produtos ao consumidor, pois ela está ligada diretamente a diversos setores, como: previsão da demanda, gestão de estoques, armazenagem, design de redes de distribuição, entre outros (OLIVEIRA, 2020). 
Faria e Costa (2011, p. 22), tratam a Logística como um macroprocesso, que é composto por três processos básicos: "Abastecimento (obtenção de materiais e componentes nacionais e importados), Planta (suporte à manufatura) e Distribuição (entrega do produto ao cliente, tanto no mercado nacional como no externo, incluindo as atividades relacionadas ao pós-venda)".

Figura 1 - A cadeia de suprimentos e os processos associados

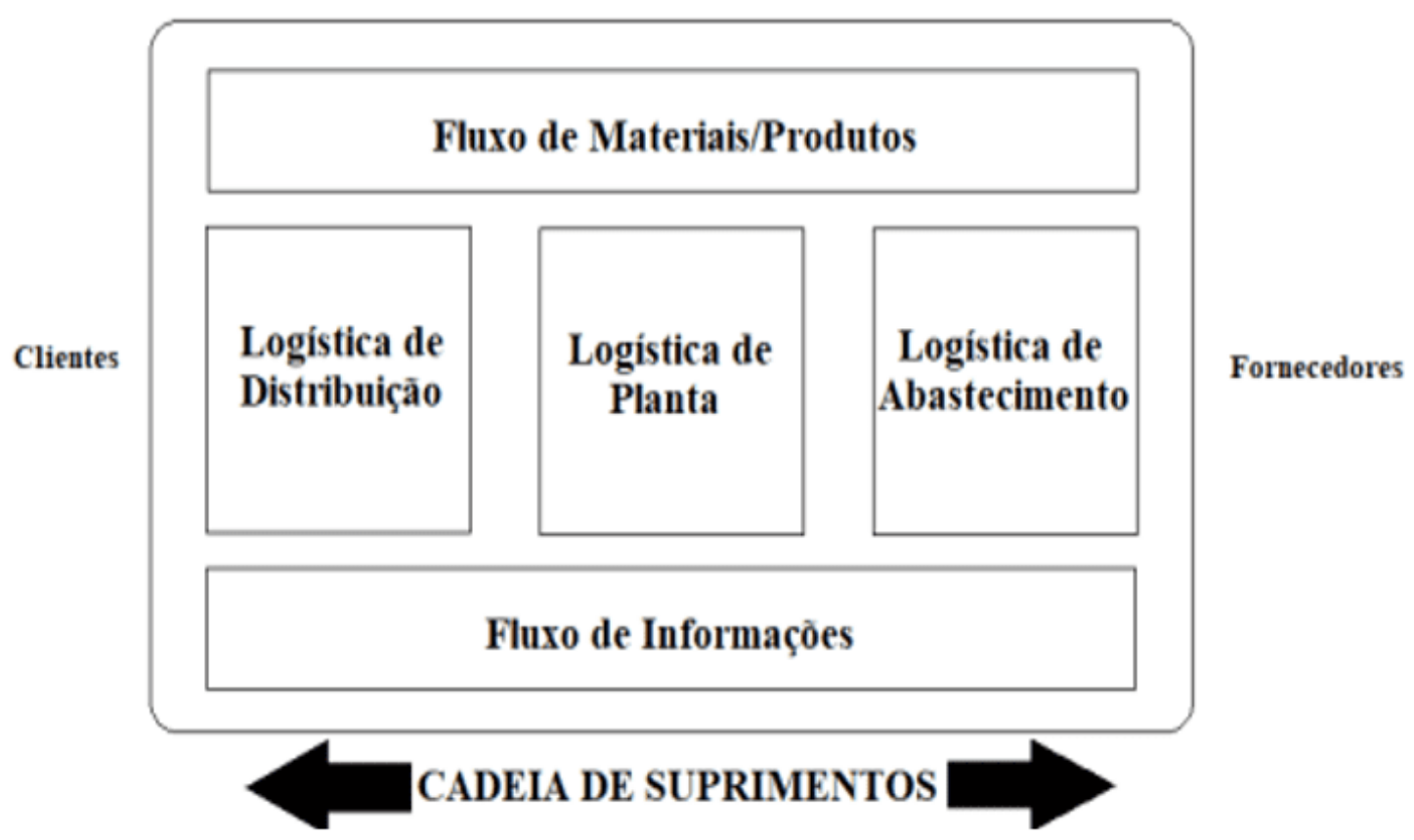

Fonte: Bowersox e Closs, (2010, p. 44)

A figura 1 mostra os processos que são realizados dentro da empresa em relação a cadeia de suprimentos e os processos associados a ela. Faria e Costa (2011) ainda colaboram com a ideia de que o processo engloba as atividades realizadas para colocar os materiais e os componentes disponíveis à disposição da produção ou distribuição, utilizando técnicas de armazenagem, movimentação, estocagem, transporte e fluxo de informações.

RC: 102110

Disponível em: https://www.nucleodoconhecimento.com.br/administracao/evolucaoe-processos 


\subsection{O QUE É LOGÍSTICA?}

Embora, popularmente, a logística esteja atrelada às empresas e aos comércios, esta não se limita apenas ao meio empresarial. Por exemplo, diariamente as pessoas precisam se planejar para chegar a um determinado destino, verificando quais modais utilizar, os horários disponíveis, as melhores rotas e os custos até o local. Logo, nota-se que todo processo de planejamento que possui um esforço integrado de ações, visando reduzir custos, satisfazer as necessidades e agregar valores, está diretamente relacionado a logística do ponto de vista comercial. A logística é a parte da metodologia em cadeia de suprimentos que delineia, implementa e controla, com eficiência, o fluxo e a armazenagem de bens, serviços e informações, desde o ponto de origem até o ponto de consumo final, de forma a atender as necessidades dos clientes (OLIVEIRA, 2020).

Ferreira (2016) entende por logística uma série de métodos e ações, em que as operações podem ser divididas em três áreas: I) aquisição (logística de suprimentos); II) apoio à produção (logística de produção) e III) distribuição ao mercado (logística de distribuição).

Logística de suprimentos: é a etapa inicial do processo, neste ponto são analisados os responsáveis pela entrada dos suprimentos, englobando desde os insumos e as necessidades do processo produtivo até liberação para a produção. Envolve as atividades de aquisição, tais como onde, como e porque comprar, assim como a seleção de fornecedores, transporte, armazenagem, gestão de estoques e informações. Logística de produção: neste ponto do processo tal metodologia visa garantir que a produção de bens e serviços sejam desenvolvidos de maneira rápida, prática e correta, pois envolve as atividades de planejamento, programação e controle da produção, abastecimento das linhas e movimentação. Logística de distribuição: este é um dos pontos finais do processo de produção que envolve desde o recebimento do produto acabado até a distribuição por meio dos canais de distribuição e/ou consumidor final, visando agregar valor ao produto e em contrapartida obter tempo e reduzir os custos sem afetar a qualidade do mesmo 
durante as etapas desenvolvidas, pois tem como principais atividades: transporte, armazenagem, gestão de estoques, informações, recebimentos de pedidos, separação de materiais, embalagem e expedição e serviço ao cliente (FERREIRA, 2016).

Como observado anteriormente, para que se alcance um alto nível de serviço com o menor custo possível é necessário atentar-se às atividades que a logística possui, podendo ser dividida em planejamento e apoio operacional, conforme mostra a figura 2.

Figura 02 - Atividades de Planejamento e apoio Operacional da logística.
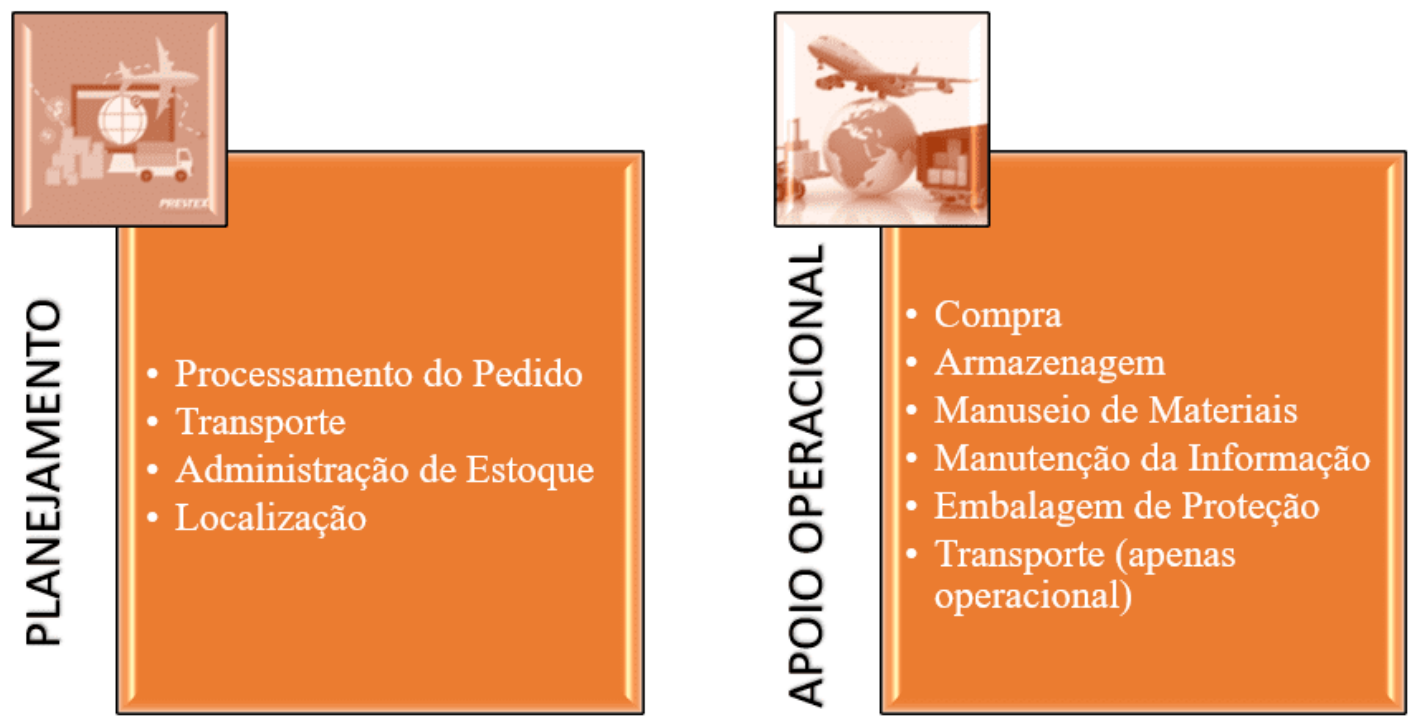

Fonte: adaptado de Rosa (2014)

A figura 2 ressalta o processo de planejamento e apoio operacional que ocorre dentro do processo logístico. O planejamento é classificado como uma macro atividade, em que, neste ponto, as principais e iniciais tomadas de decisões são acertadas; e, após estabelecidos os métodos, as formas, os recursos e os meios que serão abordados, os demais processos práticos são iniciados, tendo como cerne da estrutura das atividades: processamento, transporte, estoque e localização.

RC: 102110

Disponível em: https://www.nucleodoconhecimento.com.br/administracao/evolucaoe-processos 
O apoio operacional é considerado como atividade operacional, que envolve ações como: compra, armazenagem, manuseio de materiais, manutenção da informação, embalagem e transporte, para que o planejamento delimitado inicialmente seja executado e as demais etapas do processo realizadas corretamente. Logo, nota-se que todas as fases são importantes para que se obtenha êxito nos planejamentos logísticos (ROSA, 2014).

\subsubsection{EVOLUÇÃO DA LOGÍSTICA}

A origem da "logística" conhecida atualmente, não é exata. No entanto, acredita-se que a base logística esteja atrelada a táticas militares, mesmo que subjetivamente. É possível observar que toda ação de planejamento, estratégia e gerenciamento de recursos, tais como mão de obra, material, transporte, entre outros, já eram desenvolvidos por povos antigos em suas estratégias de exploração e ocupação territorial, em que planejavam onde, como e de que forma fariam suas invasões, isso com base no estudo prévio dos elementos disponíveis e dos melhores métodos possíveis.

Nesse contexto, a primeira vez que o termo Logística foi utilizado como uma ciência e teve teorias desenvolvidas, foi no ano de 1917, em que o Tenente-Coronel Thorpe publicou o livro "Logística Pura: a ciência da preparação para a guerra". Pode-se observar que no período da Segunda guerra novas metodologias foram desenvolvidas para o gerenciamento de informações e monitoramento de bens militares. Assim sendo, tais ideias corroboraram para a evolução da logística moderna (SANTOS, 2010)

Em termos históricos, a evolução da logística se deu desta forma: antes da década de 1940 a logística baseava-se no campo e no seu volume de produção, isto é, economia era majoritariamente agrária; limitando-se apenas a análise do transporte quanto ao escoamento dos produtos. Das décadas de 1940 a 1960 houve uma mudança na configuração dos meios de organização, em que esta buscou especializar-se no desempenho das atividades, visando os custos e indo além do 
simples deslocamento dos produtos produzidos, também envolvendo a criação de inventário; contribuindo para melhoria no controle de estoque (RAZZOLINI, 2014).

Das décadas de 1960 a 1980 o cenário buscava a integração interna com foco no cliente, buscando a eficiência na distribuição e produção dos produtos e serviços, por meio da integração das funções, de modo a alcançar lucratividade. Das décadas de 1980 a 2000, o panorama se modificou em que o destaque foi o mercado, visando a qualidade, a compra, a produção e as vendas. Usando os métodos logísticos para um diferencial competitivo e reduzindo assim, o tempo no processo gerencial. Dos anos 2000 até os anos atuais elaborou-se uma nova forma de gerenciamento denominado Supply Chain Management (Gestão da Cadeia de Suprimentos). Tal inovação logística está sendo um diferencial competitivo, contudo, as ações buscam formas de melhor administrar, flexibilizar e agilizar todas as etapas do processo de maneira a otimizar o tempo e espaço (GOMES, 2020). 
$\mathrm{Na}$ figura 3, ressalta-se a evolução da logística ao longo do tempo até os dias atuais:

\section{EVOLUÇÃO DA LOGÍSTICA}

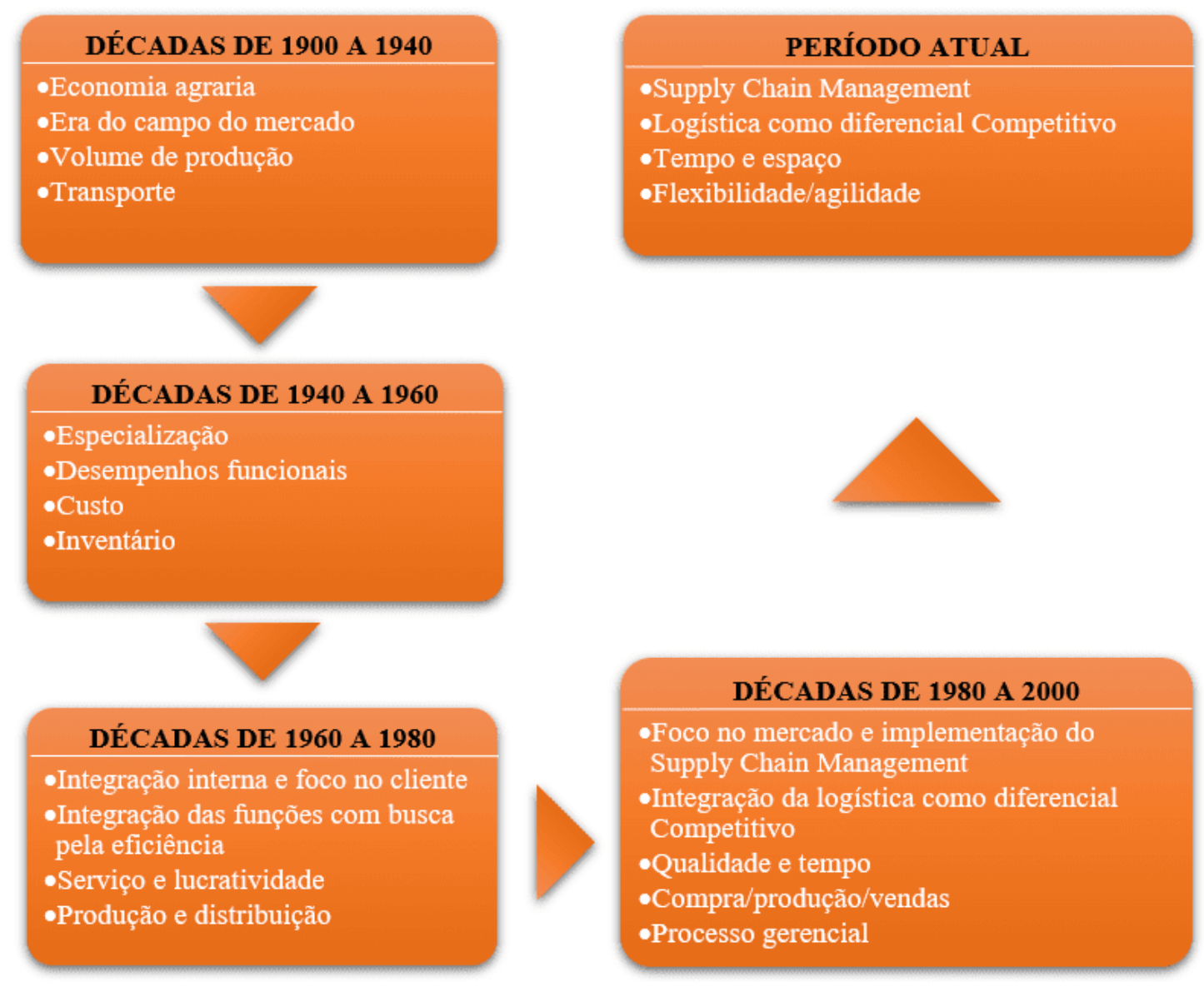

Fonte: adaptado de Rosa (2014)

Nota-se que a evolução dos processos metodológicos utilizados durante o decorrer dos anos objetivava melhorias significativas nos processos logísticos. Esses enriquecimentos contribuíram para a atual conjectura.

\subsection{ESTOQUE E ARMAZENAGEM}

O estoque e armazenagem estão associados dentro de qualquer empresa, uma vez que o armazém é a estrutura física e os estoques se referem aos itens a serem

RC: 102110

Disponível em: https://www.nucleodoconhecimento.com.br/administracao/evolucaoe-processos 
guardados no depósito. Ambos estão associados ao empreendedorismo dos processos, mas há uma diversidade entre eles, onde os estoques remetem a algo mais estático, e a armazenagem, por estar ligada aos sistemas e métodos, promove a ideia de algo totalmente dinâmico. Contudo, o estoque é um ativo importante e de grande valor. Gerir o estoque se tornou cada vez mais complexo considerando que a má gestão pode trazer perdas que influenciam nos resultados da organização (BERNARDI, 2018).

Além disso, a armazenagem é considerada uma das atividades de apoio ao processo logístico, que dão suporte ao desempenho das atividades primárias, para que a empresa possa ter sucesso, mantendo e conquistando clientes através do atendimento ao mercado (PAOLESCHI, 2014).

O armazenamento e o estoque são essenciais para as empresas em geral, pois é onde se concentram todos os itens que trarão um benefício futuro para a entidade, tais como: matéria-prima, produtos em processo de desenvolvimento, insumos ou produtos acabados (SANTOS, 2018).

Portanto, é válido enfatizar a importância do controle do armazenamento e dos estoques para maior satisfação nos resultados da organização, sendo os itens bem alocados até o seu processamento, com o objetivo de alcançar o equilíbrio entre as compras, o armazenamento e as entregas. Toda essa política facilita o recebimento, a preparação e o envio dos produtos aos consumidores.

\subsection{ANÁLISE DOS CUSTOS LOGÍSTICOS}

A análise dos custos com a logística envolve todos os gastos envolvidos neste processo, e sua importância se dá em razão da análise dos valores monetários disponibilizados pelas empresas, a fim de servirem como base para a tomada de decisões estratégicas nas empresas, dentro dos custos totais de uma organização. Identificar e mensurar estes custos de maneira exata, é vital para a sobrevivência das empresas.

RC: 102110

Disponível em: https://www.nucleodoconhecimento.com.br/administracao/evolucao- 
O objetivo da logística é estabelecer métodos que possibilitem a redução de custos desnecessários às empresas e promova uma melhoria significativa quanto ao nível de serviço oferecido aos seus clientes. Logo, a logística empresarial é analisada como o fator chave para um bom resultado da empresa, porque:

$\mathrm{Na}$ estratégia de liderança em custo, a empresa deve apresentar os menores custos do segmento em comparação com as outras organizações concorrentes. Foi no processo de adequação a essa estratégia que muitas empresas passaram a perceber a importância de uma correta gestão dos custos logísticos, que até então não eram cuidadosamente analisados pela gerência estratégica (ANDRADE, 2018, p. 19).

Por conseguinte, com o avanço tecnológico, a logística empresarial cresceu, deixando seu conceito principal de lado. Logo, a logística avançada vem sendo relevante para as empresas em geral, onde todo o processo, desde a chegada de seus insumos para a produção do produto até a entrega do mesmo ao seu consumidor final, tem gerado um grande benefício à sociedade, reduzindo custos às empresas, qualificando seus produtos e levando-os até seus clientes com uma ótima qualidade e baixo custo (DOMENEGATTO e PEREIRA, 2018).

Tendo em vista o crescimento da logística, alguns fatores impactam diretamente no valor de venda do produto para o consumidor final. A logística vem se tornando essencial nas empresas, uma vez que torna todo o processo mais eficaz e eficiente para uma qualidade de serviço. Esse custo dentro de qualquer empresa deve ser exigível, servindo de base para um controle total dos custos, verificando seu impacto nos resultados da contabilidade da empresa (NOVAES, 2021).

\subsubsection{CUSTOS COM TRANSPORTES E FRETES}

As empresas em geral necessitam de transportes. É fundamental o planejamento assertivo das operações das atividades logísticas levando em conta os cuidados especiais que devem ter, e não se esquecendo de optar por um frete de entrega de qualidade e eficaz, que se destaca com os cuidados e o tempo de entrega até o consumidor final (LEMOS, 2017).

RC: 102110

Disponível em: https://www.nucleodoconhecimento.com.br/administracao/evolucao- 
Segundo pesquisas realizadas pela Organização das Nações Unidas para a Alimentação e a Agricultura (FAO), estima-se que um terço dos alimentos feitos para o consumo humano é perdido no processo após a colheita quanto aos meios de transportes e armazenamento.

Nesse contexto, esses desperdícios de alimentos envolvem uma "logística de movimentação inadequada", observando ainda transportes e fretes de baixos custos que aumentam a probabilidade de uma perda além do esperado (QUARTAROLLI, 2020).

Os transportes e os fretes, em qualquer segmento do mercado, devem ser bem analisados, pois uma boa logística de transporte é essencial para uma boa entrega de produtos ao consumidor final. Logo, é necessário o controle adequado da higiene e conservação dos produtos, e, ainda, do tempo necessário para a execução da entrega. No que diz respeito às perdas de produtos em processos logísticos, um dos setores que apresenta maior risco no processo de transporte dos insumos é o setor agrícola, devido ao tempo de locomoção, cuidado com a temperatura, higiene, armazenamento, entre outros.

A tabela 01 apresenta dados das perdas no processo logístico por etapas.

Tabela 1 - Distribuição das perdas por etapa logística.

\begin{tabular}{l} 
DISTRIBUIÇÃO DAS PERDAS POR ETAPA \\
LOGÍSTICA \\
Porto - $9,0 \%$ \\
\hline Multimodal Ferroviário - $8,8 \%$ \\
\hline Multimodal Hidroviário - $1,6 \%$ \\
\hline Transporte Rodoviário - $13,3 \%$ \\
\hline Rodoviário Fazenda-Armazém - $21,7 \%$ \\
\hline Armazenagem Fazenda - $6,7 \%$ \\
\hline Armazenagem Externa - $38,8 \%$ \\
\hline
\end{tabular}

RC: 102110

Disponível em: https://www.nucleodoconhecimento.com.br/administracao/evolucaoe-processos 
TOTAL $-100 \%$

Fonte: Pera (2017)

Visto que o custo com essa logística é alto, é necessário avaliar o custo-benefício entre um transporte barato e um de custo mais elevado, visando optar pelo que tomará todos os devidos cuidados durante o processo de transporte, apresentando baixo índice de perda. Nesse processo de escolha, é importante analisar o máximo de transportadoras possível e medir a eficácia e eficiência na realização do transporte, explorando os feedbacks dos clientes às empresas a respeito de manuseio adequado, tempo decorrido para entrega e cuidados adotados com os respectivos carregamentos, atentando minuciosamente a cada etapa até o fim da entrega, a fim de coletar informações para escolher a melhor transportadora para realização de entregas (DEIMLING, 2016).

\subsubsection{CUSTOS COM TRIBUTOS}

Fazer a apuração dos tributos cobrados pelo governo, é dever de todas as organizações que possuem fins lucrativos, pois o pagamento de tributos não é facultativo, portanto, compete ao contribuinte pagar e ao governo instituir e cobrar (LOVISON, 2014)

Entende-se por tributo as cobranças obrigatórias instituídas em lei que devem ser pagas por uma determinada empresa, sendo o tributo uma obrigação onde existe uma relação jurídica. Sendo assim, os tributos que incidem para as empresas do segmento alimentício são: ICMS (imposto sobre circulação de mercadorias), COFINS (contribuição para o financiamento da seguridade social sobre vendas), CSLL (contribuição social sobre o lucro líquido), PIS (programa de interação social, IPI (imposto sobre produtos industrializados) e IRPJ (imposto de renda de pessoa jurídica) (SERAFINI, 2018).

O ICMS é de competência do estado e do distrito federal, sendo o imposto que geralmente tem a maior carga tributária. Analisando que o tributo incide sobre a RC: 102110

Disponível em: https://www.nucleodoconhecimento.com.br/administracao/evolucaoe-processos 
circulação de mercadoria e serviço, ele só é cobrado quando uma propriedade é passada de empresa para empresa ou de uma empresa para seus clientes, assim, quando esse fato ocorre, nomeia-se de fato gerador para cobrança do imposto.

COFINS é um tributo federal que incide entre pessoas jurídicas e empresas, e tem como base de cálculo a receita bruta mensal da entidade, tendo como seu fato gerador sempre o faturamento da empresa.

CSLL é de relevância federal para o aumento da seguridade social do país. É dever das empresas que têm localidade nacional pagar o tributo.

O PIS trata-se de um programa onde as empresas depositam contribuições destinadas aos seus empregados do setor privado e tem sua base de cálculos em cima da receita operacional bruta da pessoa jurídica, sem deduções.

O IPI incide em produtos nacionais ou importados que de alguma forma passaram por um processo de industrialização, e é de competência federal. Esse tributo, diferente do ICMS, é cobrado sobre a nota fiscal de forma separada.

Não diferente dos outros tributos, o IRPJ é um tributo federal e deve ser pago por aqueles que possuem um CNPJ ativo, com algumas exceções. $E$ tem como base de cálculo o regime tributário de pessoa jurídica.

No gráfico 1 tem-se os gastos tributários referente ao ano de 2018.

RC: 102110

Disponível em: https://www.nucleodoconhecimento.com.br/administracao/evolucaoe-processos 
Gráfico 01 - Gastos Tributários - Estimativas Bases Efetivas 2018.

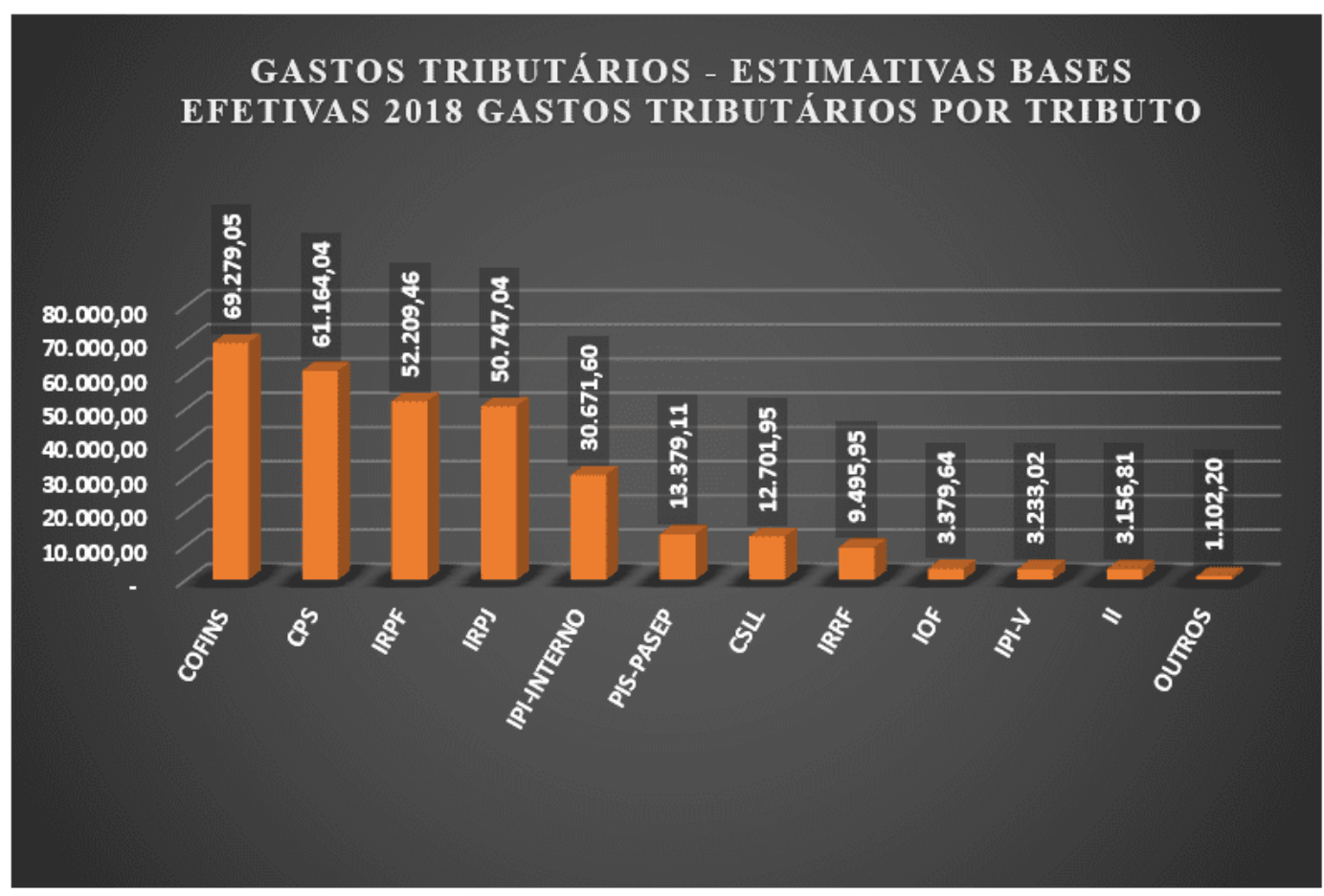

Fonte: adaptado do site da Receita Federal

Na tabela 2 é possível observar os gastos tributários detalhadamente:

Tabela 02 - Gastos tributários.

\begin{tabular}{|l|l|l|}
\hline GASTOS TRIBUTÁRIOS & VALOR & $\%$ \\
\hline Contribuição para o Financiamento da Seguridade & $\mathrm{R} \$$ & $22,31 \%$ \\
\hline Social - COFINS & $69.279,05$ & \\
\hline Contribuição para a Previdência Social - CPS & $\mathrm{R} \$$ & $19,70 \%$ \\
\hline Imposto sobre a Renda Pessoa Física - IRPF & $61.164,04$ & \\
\hline Imposto sobre a Renda Pessoa Jurídica - IRPJ & $\mathrm{R} \$$ & $16,81 \%$ \\
\hline Imposto sobre Produtos Industrializados & $-\mathrm{R} \$$ & \\
\hline
\end{tabular}

RC: 102110

Disponível em: https://www.nucleodoconhecimento.com.br/administracao/evolucaoe-processos 


\begin{tabular}{|c|c|c|}
\hline Operações Internas - IPI-Interno & $30.671,60$ & \\
\hline Contribuição Social para o PIS-PASEP & $\begin{array}{l}R \$ \\
13.379,11\end{array}$ & $4,31 \%$ \\
\hline Contribuição Social sobre o Lucro Líquido - CSLL & $\begin{array}{l}\mathrm{R} \$ \\
12.701,95\end{array}$ & $4,09 \%$ \\
\hline Imposto sobre a Renda Retido na Fonte - IRRF & $\begin{array}{l}\mathrm{R} \$ \\
9.495,95\end{array}$ & $3,06 \%$ \\
\hline Imposto sobre Operações Financeiras - IOF & $\begin{array}{l}\mathrm{R} \$ \\
3.379,64\end{array}$ & $1,09 \%$ \\
\hline $\begin{array}{l}\text { Imposto sobre Produtos Industrializados - } \\
\text { Vinculado à Importação - IPI-Vinculado }\end{array}$ & $\begin{array}{l}\mathrm{R} \$ \\
3.233,02\end{array}$ & $1,04 \%$ \\
\hline Imposto sobre Importação - II & $\begin{array}{l}\mathrm{R} \$ \\
3.156,81\end{array}$ & $1,02 \%$ \\
\hline $\begin{array}{l}\text { Adicional ao Frete para a Renovação da Marinha } \\
\text { Mercante - AFRMM }\end{array}$ & $\begin{array}{l}\mathrm{R} \$ \\
1.036,04\end{array}$ & $0,33 \%$ \\
\hline Imposto sobre Propriedade Territorial Rural - ITR & $\begin{array}{l}\mathrm{R} \$ \\
43,37\end{array}$ & $0,01 \%$ \\
\hline $\begin{array}{l}\text { Contribuição para o Desenvolvimento da Indústria } \\
\text { Cinematográfica Nacional - CONDECINE }\end{array}$ & $\begin{array}{l}\mathrm{R} \$ \\
19,99\end{array}$ & $0,01 \%$ \\
\hline $\begin{array}{l}\text { Contribuição de Intervenção no Domínio Econômico } \\
\text { - CIDE }\end{array}$ & $\begin{array}{l}R \$ \\
2,80\end{array}$ & $0,00 \%$ \\
\hline TOTAL & $\begin{array}{l}\mathbf{R} \$ \\
310.519,88\end{array}$ & $100,00 \%$ \\
\hline
\end{tabular}

Fonte: adaptado do site da Receita Federal.

O gráfico 1 e a tabela 2 são demonstrativos de impostos e tributos com estimativa de gastos por tributo. 


\subsubsection{DIMINUIÇÃO DOS CUSTOS LOGÍSTICOS}

Diminuir os custos logísticos de uma empresa para obtenção de um resultado satisfatório no final de cada mês é o objetivo de qualquer empresário, mas é um ponto que exige muita cautela. É necessário analisar e encontrar quais custos devem ser reduzidos para ter esse resultado tão esperado, sem perder sua credibilidade e continuar com um serviço eficiente e eficaz para levar até seus clientes um produto de qualidade, principalmente quando se trata de uma empresa do segmento alimentício que tem um impacto social muito grande.

Com a alta competitividade no mercado regional ou nacional, essas empresas praticamente são forçadas a diminuir suas despesas com as operações, passando a ter controle das operações que envolvem a logística, quase que obrigatoriamente (ARAÚJO, 2017, p. 137)

Alguns elementos vêm sendo fundamentais para a competitividade, como a qualidade dos produtos e a padronização dos processos. Estes potencializam a qualidade dos produtos, tendo um impacto imediato no custo. A terceirização do transporte de cargas é uma forma de obter menor custo, uma vez que a empresa não possui grandes encomendas para que lhe seja necessário ter uma equipe de transporte própria (PAULETTI, 2019).

É de interesse de todas as empresas o assunto sobre custos logísticos, uma vez que este tanto pode impactar positivamente a contabilidade no final de cada mês quanto pode ser prejudicial para a entidade, visto que são reduzidos alguns custos necessários a empresa para um produto de qualidade e um processo qualificado para uma produção eficiente. Tende-se observar quais os custos desnecessários, quais os importantes e quais aqueles que podem ser apenas reduzidos como o processo de embalagem.

\subsection{TECNOLOGIA LIGADA A LOGÍSTICA}

Como mencionado anteriormente, a logística é essencial para as empresas. O conjunto: planejamento e execução, permite o controle total e eficiente quanto ao 
armazenamento, movimentação e transporte dos produtos e seus insumos dentro e fora da empresa. A tecnologia simplesmente simplifica o processo da logística facilitando o acesso aos dados. Com um maior controle, as atividades são executadas de forma automática tornando a equipe mais produtiva. Os avanços tecnológicos ao longo da história favoreceram a integração das atividades logísticas por meio do fluxo de informações (SILVA, 2020).

Atualmente, o mercado exige qualidade dos serviços com uma efetividade maior. Tendo em vista os desejos e as necessidades dos clientes, as entidades passaram a atender todas as necessidades possíveis, com uma logística eficiente e eficaz. A logística contribui para se destacar em meio a concorrência, atraindo e ganhando mais consumidores (GHISLERE, 2019).

O avanço tecnológico na área logística das empresas favoreceu a realização de entregas mais rápidas e seguras, impulsionando a inovação nesse setor. Assim como, os softwares também trouxeram, no setor de armazenagem e estoque, diversas funcionalidades, permitindo o registro dos recebimentos, do inventário e da separação dos pedidos, além da rapidez para conferir determinado item. Com essa eficiência pode-se gerar uma redução de custo para um excelente resultado.

\section{MATERIAIS E MÉTODOS}

Os materiais e métodos mostram os caminhos percorridos para o alcance de um determinado fim, que tem como objetivo mostrar como o trabalho foi realizado e desenvolvido. Os materiais e métodos compreendem o planejamento detalhado sobre tudo que foi realizado durante o processo de elaboração. Zanella (2013) afirma que no âmbito científico os métodos são a forma escolhida para expandir seu conhecimento se aprofundando e obtendo uma visão ampla sobre determinado objeto, fato ou fenômeno. Para Menezes et al. (2019), a escolha da metodologia utilizada deve proporcionar uma leitura clara dos objetivos propostos na pesquisa. 
Portanto, o trabalho utilizou-se de diversas ferramentas, formas e métodos, para obtenção de embasamento teórico sobre o tema proposto.

\subsection{PROCEDIMENTOS METODOLÓGICOS}

Os procedimentos metodológicos mostram o tipo de pesquisa realizada em um trabalho, abrangendo a escolha das técnicas e métodos aplicados no desenvolvimento da pesquisa. Conforme Vergara (2016), o método científico é um caminho, uma forma e/ou uma lógica de pensamento. Havendo basicamente três grandes métodos, tais como: hipotético-dedutivo; fenomenológico; e dialético.

\subsubsection{QUANTO À NATUREZA}

A natureza diz respeito à contribuição e à finalidade de uma pesquisa. Para Pereira et al. (2018, p. 12) "existem diversos métodos, e cabe ao pesquisador, dependendo do objeto e da natureza da pesquisa, selecionar o método de abordagem que entender mais adequado para a sua investigação científica".

Assim, para Minayo (2010, p. 46), a metodologia é "mais que uma descrição formal dos métodos e técnicas a serem utilizados, indica as conexões e a leitura operacional que o pesquisador fez do quadro teórico e de seus objetos de estudo".

Logo, quanto à natureza, este estudo trata-se de uma pesquisa qualitativa, pois os dados coletados foram retirados de pesquisas bibliográficas de acordo com a proposta de pesquisa.

\subsubsection{QUANTO AOS FINS}

Toda pesquisa possui um propósito ao ser desenvolvida. Diante disso, esta pesquisa é descritiva, pois buscou descrever os processos logísticos, bem como a diminuição dos custos desses processos para a empresa. De acordo com Lima e Pereira (2018), a pesquisa descritiva permite descrever e analisar os dados encontrados sem que haja interferência do pesquisador. 


\subsubsection{QUANTO AOS MEIOS}

Esta pesquisa foi realizada por meio de pesquisas bibliográficas a partir da leitura de livros e artigos já publicados. Menezes et al. (2019, p. 32) afirmam que "uma das possibilidades de classificar os tipos de uma pesquisa é observar os seus objetivos. Para Aragão (2017 p. 34)

os procedimentos e técnicas adequadas ao desenvolvimento da pesquisa estão diretamente ligados tanto ao problema de pesquisa criado a partir do tema, quanto à consecução dos objetivos específicos que irão embasar as análises e interpretação dos resultados obtidos na pesquisa de campo.

Essa etapa do estudo reuniu informações a partir do estudo qualitativo e descritivo que serviram para a construção da proposta da pesquisa, baseado em pesquisas para observar, coletar, analisar e interpretar os dados, a fim de identificar a melhor solução a ser tomada.

\section{CONSIDERAÇÕES FINAIS}

Com o crescimento contínuo da competitividade e exigência do mercado, as empresas que se destacam são as que buscam não apenas apresentar um simples produto, mas propor uma experiência aos seus clientes. E um planejamento logístico coopera para uma abordagem mais eficiente e prática direcionada ao alcance das metas estabelecidas.

O planejamento correto desenvolvido dentro de uma empresa deve ser visto como de grande valia para o controle das atividades, proporcionando maior domínio das ações logísticas; assim como os investimentos em tecnologias de automação nas possíveis etapas de criação, produção e entrega, que fornece melhorias significativas na gestão de dados, estocagem e transporte.

O gerenciamento logístico, atrelado aos serviços contábeis, promove progressos para as entidades e, em contrapartida, qualidade para a sociedade. A tecnologia é um fator importante que impacta diretamente na logística, logo, investir no

RC: 102110

Disponível em: https://www.nucleodoconhecimento.com.br/administracao/evolucaoe-processos 
desenvolvimento do uso tecnológico dentro dos processos logísticos é fundamental. Além de impactar diretamente nas etapas de armazenagem, estoque, transporte, entre outras, a logística torna o método adotado mais ágil e prático de ser desempenhado e, ainda, proporciona um menor custo, gerando um lucro maior à empresa por meio de procedimentos.

Nesse contexto, a pergunta norteadora deste estudo é: como ocorre a evolução da logística bem como os custos e processos? Obteve-se, portanto, como resposta, que os avanços dos estudos sobre a redução dos custos, evolução da logística e custos com tributos são constantes e devem ser melhor investigados juntamente com os demais processos que acontecem dentro da organização e que utilizam a logística.

Portanto, conclui-se que os processos de custos logísticos, bem como a evolução da logística é essencial para empresa, porque possibilita a compreensão dos processos no que concerne a logística dentro da empresa, e ajuda a evitar gastos desnecessários, visto que o objetivo da logística é estabelecer métodos que possibilitem a redução de custos desnecessários às empresas.

\section{REFERÊNCIAS}

ANDRADE, N. F. Custos logísticos para centralização/descentralização de estoque em uma empresa varejista de alimentos congelados. Brasília, 2018.

ARAGÃO, J. W. M. de.; NETA, M. A. H. M. Metodologia Científica. [recurso eletrônico] - Salvador: UFBA, Faculdade de Educação, Superintendência de Educação a Distância, 2017.

ARAUJO, F. Otimização de rota e redução dos custos logísticos: estudo de caso em uma empresa de contabilidade. Uberlândia - MG, 2017.

BENITTEZ, R. O. Perdas e desperdícios de alimentos na América Latina e no Caribe.

Notícias.

FAO.

Disponível em:

RC: 102110

Disponível em: https://www.nucleodoconhecimento.com.br/administracao/evolucaoe-processos 
$<$ http://www.fao.org/americas/noticias/ver/pt/c/239394/>. Acesso em: 15 de set. de 2021.

BERNARDI, G. H. D. Avaliação de Controle de Estoque: Uma Análise de Caso na Empresa Juína Cabos. AJES - Faculdade do Vale do Juruena, Juína-MT, 2018.

BOWERSOX, D. J; CLOSS, D. J. Logística Empresarial - 0 processo de integração da cadeia de suprimentos. 1. ed. São Paulo: Atlas, 2010.

DEIMLING, M. F. et al. Análise da influência da logística de transportes rodoviários no custo Brasil. Revista de Administração do UNIFATEA, v. 13, n. 13, 2016.

DOMENEGATTO, K. F.; PEREIRA, D. C. Estudo do serviço logístico de uma empresa do ramo alimentício no oeste do Paraná. Paraná, 2018.

FARIA, A. C.; COSTA, M. F. G. Gestão de Custos Logísticos. São Paulo: Editora Atlas, 2011.

FERREIRA, L. et al. Processos logísticos. Londrina: Editora e Distribuidora Educacional S.A., 2016.

GHISLERE, C. A. R. Transporte terceirizado na indústria de alimentos. Londrina, 2019.

GOMES, C. F. S.; RIBEIRO, P. C. C. Gestão da cadeia de suprimentos integrada à tecnologia da informação. Editora Senac Rio, 2020.

ILOS. Instituto de Logística e Supply Chain. Cenário da Estrutura Rodoviária no Brasil. ILOS, 2016. Disponível em:< http://www.ilos.com.br/web/ >. Acesso em out. de 2021.

LEMOS, F. O. R. de. A segurança alimentar nos transportes. Resende: AMAN, 2017.

RC: 102110

Disponível em: https://www.nucleodoconhecimento.com.br/administracao/evolucao- 
LIMA, P. G.; PEREIRA, M. C. (orgs). Pesquisa científica em ciências humanas: uma introdução aos fundamentos e eixos procedimentais. Uberlândia, Navegando Publicações, 2018.

LOVISON, M. A. O impacto da substituição tributária do ICMS na formação dos preços de vendas em uma indústria alimentícia. Caxias do Sul, 2014.

MENEZES, A. H. N. et al. Metodologia científica: teoria e aplicação na educação a distância. Petrolina -PE, 2019.

MINAYO, M. C. S. (Org.) Pesquisa social: teoria, método e criatividade. 29. ed. Petrópolis: Vozes, 2010.

NOVAES, A. G. Logística e gerenciamento da cadeia de distribuição: estratégia, operação e avaliação. 5. Ed., ver. e atual., São Paulo: Atlas, 2021.

OLIVEIRA, D. S. et al. Análise Multidimensional dos Custos Logísticos contribuindo à Gestão de uma Empresa de Contabilidade. ABCustos, v. 15, n. 2, 2020.

PAOLESCHI, B. Cadeia de suprimentos. 1. ed. São Paulo: Érica, 2014.

PAULETTI, D. et al. Padronização e redução de custos: 0 caso da unificação de shelf life de embalagens plásticas frigorificadas. Curitiba, 2019.

PÉRA, T. G. Modelagem das perdas na agrologística de grãos no Brasil: uma aplicação de programação matemática. São Paulo, 2017.

PEREIRA, A. S. et al. Metodologia da pesquisa científica. [recurso eletrônico] 1. ed. Santa Maria, RS: UFSM, NTE, 2018.

QUARTAROLLI, L. A. C. O desafio do transporte de alimentos in natura: uma reflexão sobre sua importância em tempos de pandemia. Sorocaba, 2020. 
RAZZOLINI, E. F. Logística: evolução na administração - desempenho e flexibilidade. 2. ed. Curitiba: Juruá, 2014.

RFB. Receita Federal do Brasil. Demonstrativo dos Gastos Tributários Bases Efetivas - 2018 Série 2016 a 2021. Brasília, 2021. Disponível em: < https://www.gov.br/receitafederal/pt-br/acesso-a-informacao/dados-

abertos/receitadata/renuncia-fiscal/demonstrativos-dos-gastos-tributarios/arquivos-eimagens/dgt-bases-efetivas-2018-serie-2016-a-2021-base-conceitual-e-gerencial.pdf >. Acesso em: 13 de set. de 2021.

ROSA, R. de A. Gestão logística. 3. ed. rev. atual. Florianópolis: Departamento de Ciências da Administração, 2014.

SANTOS, J. C. D. et al. Logística: Evolução e perspectiva. Revista de Ciências Empresariais, v. 2, n. 4, p. 1-14, 2010.

SANTOS, R. O. Estudo para armazenamento compartilhado em centros comerciais. Uberlândia - MG, 2018.

SERAFINI, F. C. O planejamento tributário como ferramenta lícita de redução da carga tributária. Cuiabá-MT, 2018.

SILVA, A. C. A tecnologia da informação na logística de suprimentos dos órgãos provedores do exército brasileiro: o caso do depósito de subsistência de Santa Maria. Salvador, 2020.

VERGARA, S. C. Projetos e relatórios de pesquisa em administração. 16. ed. São Paulo: Atlas, 2016.

ZANELLA, L. C. H. Metodologia de pesquisa. 2. ed. reimp. Florianópolis: Departamento de Ciências da Administração/ UFSC, 2013.

Enviado: Setembro, 2021. 
Aprovado: Novembro, 2021.

RC: 102110

Disponível em: https://www.nucleodoconhecimento.com.br/administracao/evolucaoe-processos 